\title{
Management of Intramedullary Spinal Cord Tumors with 26 Cases in the Department of Neurosurgery of Ibn Sina University Hospital-Rabat
}

\author{
Zakaria Chandide Tlemcani*, Mustapha Hemama, Nizar El Fatemi \\ Department of Neurosurgery, Hospital of IBN SINA, Faculty of Medicine and pharmacy of Rabat, Mohamed V University, Rabat, \\ Morocco \\ Email: jakjak0100@gmail.com
}

How to cite this paper: Tlemcani, Z.C., Hemama, M. and El Fatemi, N. (2021) Management of Intramedullary Spinal Cord $\mathrm{Tu}$ mors with 26 Cases in the Department of Neurosurgery of Ibn Sina University Hospital-Rabat. Open Access Library Journal, 8: e8144.

https://doi.org/10.4236/oalib.1108144

Received: November 2, 2021

Accepted: November 23, 2021

Published: November 26, 2021

Copyright () 2021 by author(s) and Open Access Library Inc.

This work is licensed under the Creative Commons Attribution International License (CC BY 4.0).

http://creativecommons.org/licenses/by/4.0/

\begin{abstract}
Intramedullary spinal cord tumors are relatively rare neoplasms of all Central Nervous System (CNS) tumors. Their treatment and prognosis are largely dependent on tumor histology and patient functionality. The introduction and breakthroughs of microsurgical techniques have made surgery the mainstay of treatment for intramedullary tumors. We performed a retrospective analysis of 26 cases of primitive intramedullary spinal cord tumors treated between 2013 and 2019 at the Neurosurgery Department of Ibn SINA University Hospital of Rabat. In our patient's population, the sex ratio was 1.75 showing with a predominance of male over female patients. The median age was 26 years old. The clinical symptomatology is dominated by a slow medullar compression. Spinal magnetic resonance imaging (MRI) was performed for all the patients and led to the positive diagnosis in all cases with a radio-histological correlation in $54.4 \%$ of the cases. The treatment was surgical in all cases by laminectomy in posterior access. This surgery has allowed a complete tumoral resection. Histological examination of the tumor was done for all patients and led to diagnosis confirmation in all cases. Understanding intramedullary spinal tumor is imperative to design proper management and obtain optimal patient outcomes. In addition, a meticulous operative technique and the use of surgical adjuncts are essential to accomplish proper tumor removal, diminish the risk of recurrence, and preserve neurologic functions.
\end{abstract}

\section{Subject Areas}

Clinical Trials, Neurology 


\section{Keywords}

Intramedullary Spinal Cord Tumor, Complete Removal, Microsurgical Technique

\section{Introduction}

Intramedullary spinal cord tumors are rare primary spine neoplasms of the CNS. It accounts for $2 \%-5 \%$ of CNS neoplasms in adults and it remains a clinical challenge due to potential delay in diagnosis and limited therapeutic options [1] [2].

The most common types are Ependymomas, Astroctyomas, Hemangioblastoma [2]. These lesions have their own hallmark characteristics; however, they remain both radiographically and clinically difficult to distinguish from one another. The Surgical resection remains the mainstay of treatment of this tumor.

The purpose of this work is to assess the service experience in terms of care of this pathology, and to compare our results with those of the literature.

\section{Material and Methods}

This is a Retrospective analysis of 26 cases of Primitive Intramedullary Spinal Cord Tumors treated between 2013 and 2019 at the Neurosurgery Department of Ibn SINA University Hospital of Rabat.

Different parameters were used from the medical records from our neurosurgery department. A pre-established operating sheet produced for this purpose enabled the collection of epidemiological, clinical, para-clinical, therapeutic and evolutionary data. These parameters are then collected and analyzed.

\section{Results}

During 7 years, we admitted 26 cases of intramedullary spinal cord tumors to our department.

\subsection{Age Repartition}

The age distribution of our cases varies from 18 to 74 years.

\subsection{Sex Ratio}

In our series, we had 10 female and 16 male (Figure 1).

\subsection{Consultation Deadline}

It is defined by the time elapsed between the first clinical sign and the diagnosis. It varied between 4 months and 6 years, with an average of 21 months.

\subsection{Clinical Exam}

We find 24 cases (92.30\%) of Motor disorder, 19 cases (73.07\%) of sensitive 
disorder, 11 cases of radicular pain $(42.3 \%)$ and 10 cases of sphincter disorder (38.46\%). We resumed this clinical finding into FRANKEL rating (Table 1).

\subsection{Imaging Finding}

T1 and T2-weighted MRI with gadolinium enhancement is the imaging modality of choice for suspected Intramedullary Spinal Cord Tumor.

We had 11 cases of cervical localization (42.30\%), 05 cases of cervico dorsal tumors, 06 cases of dorsal tumors (23.07\%) and only 4 cases of Lumbar tumors (15.38\%).

MRI finding was useful to characterize some tumors (Figures 2-5).

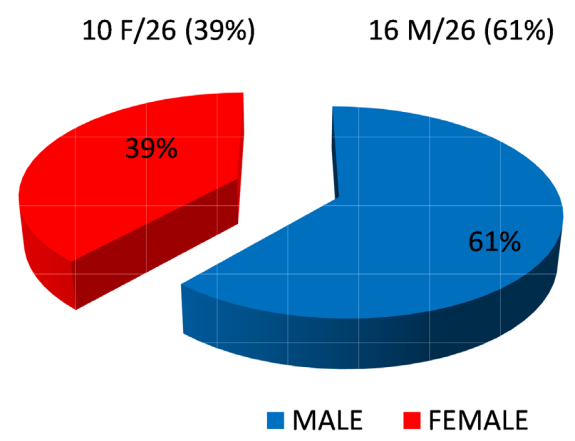

Figure 1. Sex ratio.

Table 1. Neurological status according to the FRANKEL rating.

\begin{tabular}{ccc}
\hline FRANKEL & $\begin{array}{c}\text { NUMBER OF } \\
\text { CASES }\end{array}$ & PERCENTAGE \\
\hline A: complete motor an sensory loss & 5 & $19.23 \%$ \\
B: complete motor loss, incomplete sensory loss & 9 & $34.61 \%$ \\
C: incomplete motor loss without practical use & 7 & $26.92 \%$ \\
D: incomplete motor loss, able to ambulate with or & 3 & $11.53 \%$ \\
without walking aids & 2 & $7.69 \%$ \\
\hline
\end{tabular}
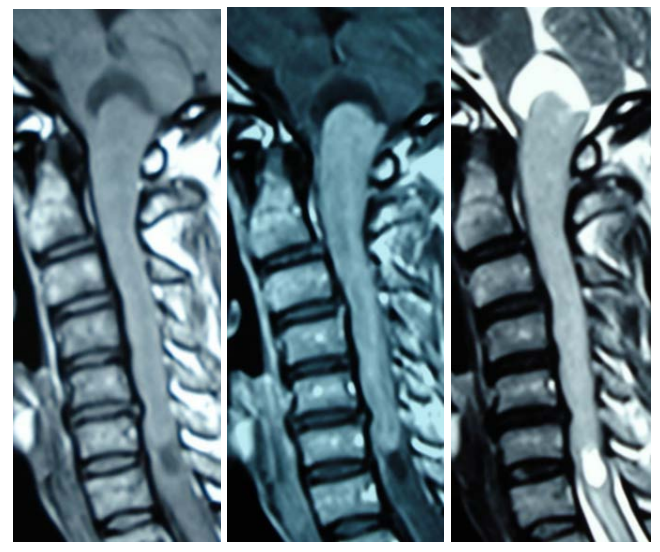

Figure 2. Ependymome (WHO grade II). 


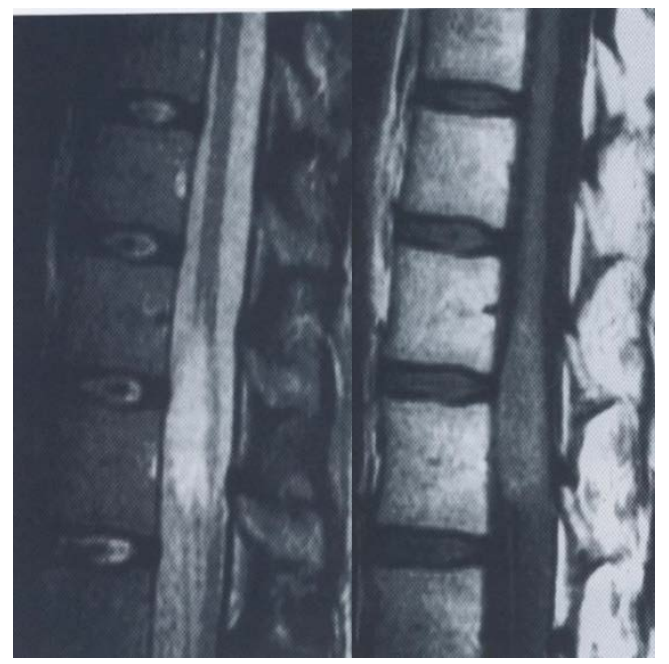

Figure 3. MRI of grade II conus astrocytoma.

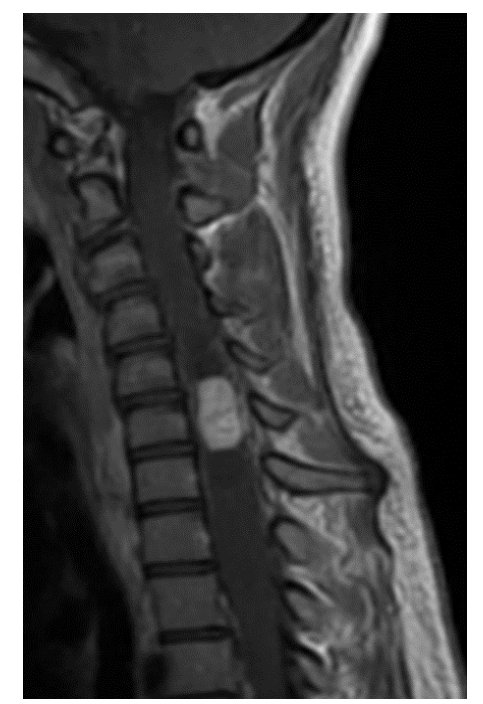

Figure 4. Spinal cord hemangioblastoma.

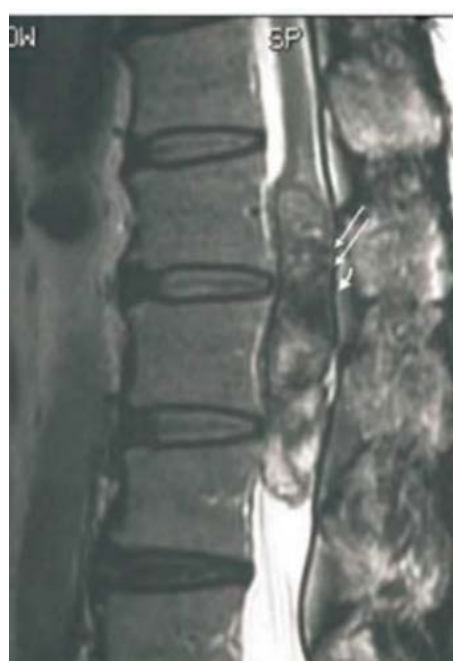

Figure 5. Spinal epidermoid cysts. 


\subsection{Surgery}

The objectives of the surgery were to perform decompression by laminectomy, to do a complete resection as possible and to confirm the diagnosis by taking a sample for histological studies.

The surgical approach of intramedullary tumors was performed under an operative microscope in all cases (100\%), and tumor resection was complete in 15 cases $(57.69 \%)$ and incomplete in 10 cases $(38.46 \%)$

Some microscopic operative image of our spinal cord tumors (Figure 6, Figure 7).

\subsection{Anatomopatholog}

The histologic study was essential to confirm the diagnosis of intramedullary tumors.

We note in our series a predominance of astrocytomas, representing $38.46 \%$ of cases (Table 2).

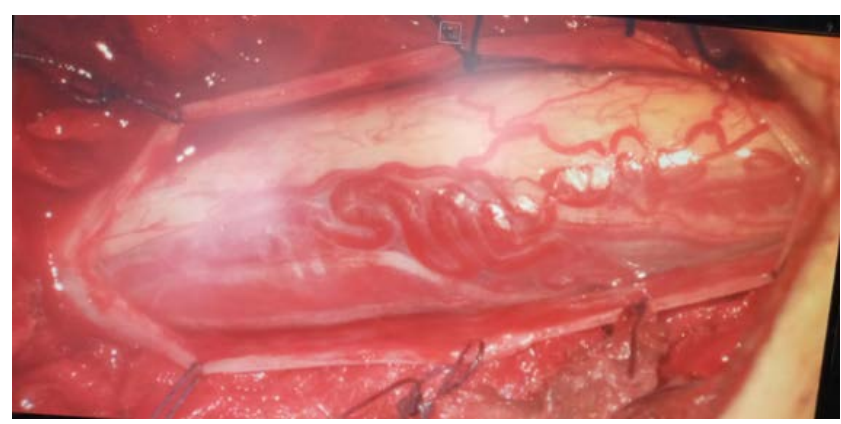

Figure 6. Spinal cord hemangioblastoma.
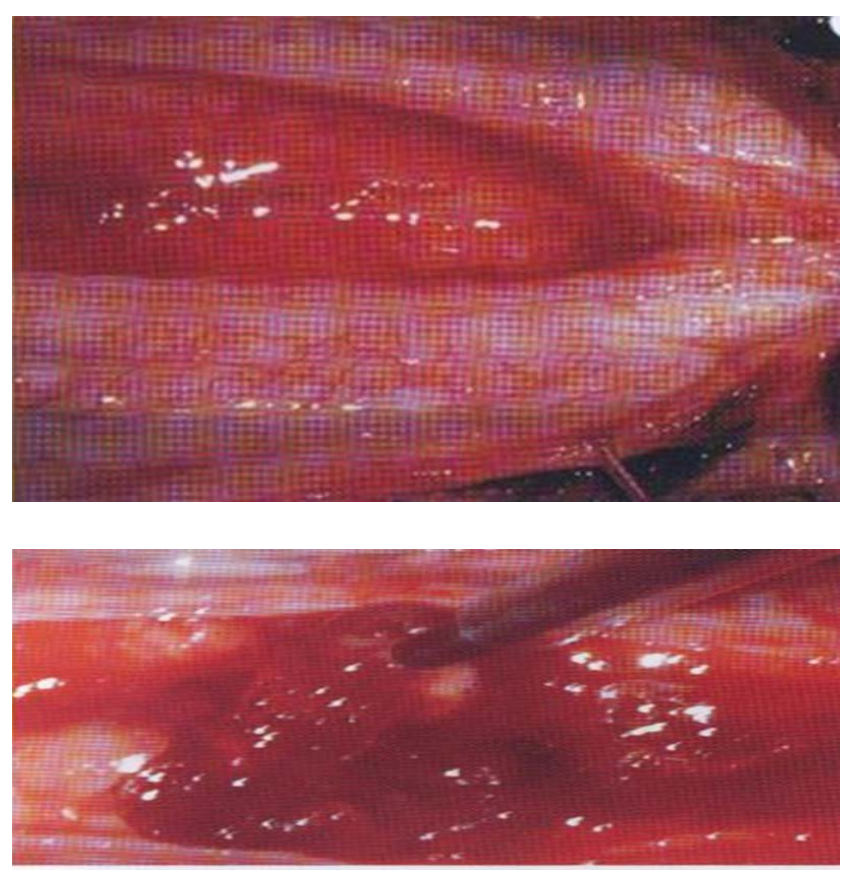

Figure 7. Surgical resection of grade II ependymoma. 
Table 2. Distribution of histological diagnoses.

\begin{tabular}{ccc}
\hline TUMOR TYPE & NUMBER OF CASES & PERCENTAGE \\
\hline Astrocytoma & 10 & $38.46 \%$ \\
Ependymoma & 8 & $30.76 \%$ \\
Hemagioblastoma & 2 & $7.69 \%$ \\
Dermoid cyct & 3 & $11.53 \%$ \\
Epidermoid cyst & 2 & $7.69 \%$ \\
Oligodendroglioma & 1 & $3.84 \%$ \\
\hline
\end{tabular}

\subsection{Evolution}

In our series, there were no cases of death and by comparing the neurological states in the immediate pre and postoperative period, we noted Improvement in 15 cases $(57.69 \%)$, worsening in 6 cases $(23.07 \%)$, and a steady state in 5 cases (19.23\%).

The postoperative consequences were simple, except for one case of meningitis on 6st day postoperative, which has progressed well under antibiotic treatment.

\section{Discussion}

\subsection{Epidemiology}

The average age of discovery of intramedullary spinal cord tumors in the literature varies between 28 and 44 years, with a maximum frequency noted in the third decade of life (Table 3 ).

Most of the series report a slight predominance of the occurrence of intramedullary spinal cord tumors in male sex.

The time taken to diagnose intramedullary tumors varies from one series to another, in the CHANDY series [6], this time varied from 3 weeks to 15 years, in our series this diagnostic timeframe varied from 4 months to 6 years with a 21-month average (Table 4).

For each tumor considered, the duration of development differs according to the grade histological.

According to the literature, hemangiomas have an average duration of evolution before the diagnosis of a year and a half.

\subsection{Clinical Finding}

Spinal pain was only revealing in $42.3 \%$ of cases in our series, while in the literature we find higher percentages. In our series, motor disorders are reported in almost all cases (92.3\%) (Table 5). On the other hand, sphincter dysfunctions tend to appear late in the course of the disease, and are initially limited to incontinence or urinary retention. In our series, they were revealing in $38.46 \%$ of cases. In the FADI series [7], these disorders were initial in $35 \%$. 
Table 3. Distribution according to the mean age of onset in the literature.

\begin{tabular}{ccc}
\hline Series & Number of cases & Average age \\
\hline KELLY [3] & 183 & 38.8 \\
DAVID [4] & 62 & 28.5 \\
OLIVER [5] & 27 & 41 \\
OUR SERIE & 26 & 36.43 \\
\hline
\end{tabular}

Table 4. Time to progression of intramedullary tumors in the literature/our series.

\begin{tabular}{ccc}
\hline Series & Number of cases & Diagnostic delay (months) \\
\hline KELLY & 183 & 36.5 \\
DAVID & 62 & 36 \\
CHANDY [6] & 68 & 31.2 \\
OUR SERIE & 26 & 21 \\
\hline
\end{tabular}

Table 5. Comparison of the clinical results of our series with the literature.

\begin{tabular}{ccccc}
\hline & SPINAL PAIN & $\begin{array}{c}\text { MOTOR } \\
\text { DISORDER }\end{array}$ & $\begin{array}{c}\text { SENTIF } \\
\text { DISORDER }\end{array}$ & $\begin{array}{c}\text { SPHINCTER } \\
\text { DYSFONCTION }\end{array}$ \\
\hline \multirow{2}{*}{ KELLY } & $122 / 183$ & $158 / 183$ & $79 / 183$ & $61 / 183$ \\
& $67 \%$ & $86.6 \%$ & $43 \%$ & $33 \%$ \\
FADI [7] & $17 / 26$ & $18 / 26$ & $15 / 26$ & $9 / 26$ \\
& $65 \%$ & $69 \%$ & $57.69 \%$ & $35 \%$ \\
OLIVER & $23 / 27$ & $20 / 27$ & $14 / 27$ & $3 / 27$ \\
& $85 \%$ & $76 \%$ & $51.85 \%$ & $11 \%$ \\
OUR SERIE & $11 / 26$ & $24 / 26$ & $19 / 26$ & $10 / 26$ \\
& $42.3 \%$ & $92.30 \%$ & $73.07 \%$ & $38.46 \%$ \\
\hline
\end{tabular}

These data are consistent with the results of our series, where the cervical was the most affected $42.30 \%$, then the thoracic level (23.07\%) (Table 6).

\subsection{Surgery}

The difficulty lies in the fact that only a radical excision can prevent recurrence, we must then find the right compromise between a maximum excision with minimal functional risk.

In our series, complete tumor resection (macroscopically) was performed in 15 patients (57.69\%) and incomplete in 10 patients (38.46\%) (Table 7).

Adjuvant radiotherapy is advocated when resection is contraindicated or if the tumor is high grade. The role of radiotherapy is controversial, however. Some studies suggest a positive outcome whilst others suggest no benefit [8]. In addition, several side effects are associated with radiotherapy such as radiation myelopathy and spinal deformities [9]. Chemotherapy also seems to have limited role and is generally used only when resection and adjuvant radiotherapy were unsuccessful. 
Table 6. Topographic distribution of intramedullary tumors.

\begin{tabular}{ccccc}
\hline & CERVICAL & $\begin{array}{c}\text { CERVICO } \\
\text { DORSAL }\end{array}$ & DORSAL & LUMBAR \\
& \multicolumn{2}{c}{$30 / 56$} & $9 / 56$ & $17 / 56$ \\
SUN [8] & $53.57 \%$ & $16.07 \%$ & $30.35 \%$ \\
& $20 / 45$ & $5 / 45$ & $15 / 45$ & $5 / 45$ \\
BERHOUMA [9] & $44.44 \%$ & $11.11 \%$ & $33.33 \%$ & $11.11 \%$ \\
OUR SERIE & $11 / 26$ cases & $5 / 26$ cases & $6 / 26$ cases & $4 / 26$ cases \\
& $42.30 \%$ & $19.23 \%$ & $23.7 \%$ & $15.38 \%$ \\
\hline
\end{tabular}

Table 7. Extent of surgical excision in the literature.

\begin{tabular}{cccc}
\hline & COMPLETE & INCOMPLETE & BIOPSIE \\
& RESECTION & RESECTION & \\
\hline \multirow{2}{*}{ SUN } & $33 / 56$ cases & $20 / 56$ cases & 3 cases \\
& $58 \%$ & $35 \%$ & $7 \%$ \\
BERHOUMA & $31 / 45$ & $11 / 45$ & $3 / 45$ \\
SANDALCIOGLU & $69 \%$ & $24.4 \%$ & $\mathbf{6 . 6 \%}$ \\
[10] & $\mathbf{6 5 / 7 8}$ & $\mathbf{9 / 7 8}$ & $\mathbf{4 / 7 8}$ \\
& $\mathbf{8 3 . 3} \%$ & $\mathbf{1 1 . 5 \%}$ & $\mathbf{5 \%}$ \\
OUR SERIE & $15 / 26$ cases & $10 / 26$ cases & 1 case \\
& $57.69 \%$ & $38.46 \%$ & $3.84 \%$ \\
\hline
\end{tabular}

\subsection{Histological Results}

The majority of authors report that the degree of tumor excision depends mainly to the type and histological grade of the tumor. In most of the published series, we note the predominance of ependymomas [10].

In our series, astrocytomas accounted for $38.46 \%$ of cases, against $30.76 \%$ of ependymoma.

The ependymoma is most often well defined and with patience, we can discover the cleavage plane that will allow the tumor to be removed as completely as possible.

The complete excision of an infiltrating tumor such as astrocytoma, has been greatly facilitated by the use of the ultrasonic scalpel CAVITRON.

\subsection{Recurrence}

For ependymomas, recurrence after complete resection is rare, with a rate not exceeding 5\%, but they can manifest after several years. In most series, the operative mortality rate is zero [9] [10] [11], this is also the case in our series.

Regular MRI is recommended every 1 - 2 years, and any possible recurrence will be best dealt with a new surgical resection.

Since astrocytomas are infiltrating lesions, their removal often leaves persistent tumor cells, which explains the high rate of local recurrence.

So, the total resection allow a good clinical improvement, and prevent longterm recurrence and decrease the morbidity, even if sometimes a subtotal resec- 
tion with radiotherapy may preserve a stable neurological status, and good local control of the lesions.

\subsection{Prognosis}

The factors positively influencing the prognosis are early Diagnosis and rapid management with a good preoperative neurological status, and rate tumor width/ Medullary width $<0.80$.

Low histological grade of the tumor is also essential prognosis factors with an extent radical surgery.

\section{Conclusion}

Understanding intramedullary spinal tumor is imperative to design proper management and obtain optimal patient outcomes. In addition, a meticulous operative technique and the use of surgical adjuncts are essential to accomplish proper tumor removal, in order to diminish the risk of recurrence, and preserve neurologic functions.

\section{Conflicts of Interest}

The authors declare no conflicts of interest.

\section{References}

[1] Clemenceau, S. and Lopez, M. (2000) Tumeurs Intramédullaires. Revue du Praticien, $50,226$.

[2] Schellinger, K.A., Propp, J.M., Villano, J.L. and Mccarthy, B.J. (2008) Descriptive Epidemiology of Primary Spinal Cord Tumors. Journal of Neuro-Oncology, 87, 173 179. https://doi.org/10.1007/s11060-007-9507-Z

[3] Koeller, K.K. and Rosenblum, R.S. and Morrison, A.L. (2000) Neoplasms of the Spinal Cord and Filum Terminal: Radiologic-Pathologic Correlation. Radiographics, 20, 1721-1749.

[4] Horth, D.P. (2002) Astrocytomes Intramédullaires: Conduite à Tenir. La lettre de neurologie, 5, 165-167.

[5] Hausmann, O.N., Kirsch, E.C., Tolnay, M. and Gratzl, O. (2001) Intramedullary Spinal Cord Tumors: A Clinical Outcome and Radiological Follow up Study. Swiss Medical Weekly, 131, 582-587.

[6] Chandy, M.J. and Babus, S. (1999) Management of Intramedullary Spinal Cord Tumors: Review of 68 Patients. Neurology India, 47, 224-228.

[7] Hanbali, F., Fourney, D.R., et al. (2002) Spinal Cord Ependymoma: Radical Surgical Resection and Outcome. Neurosurgery, 51, 1162-1174. https://doi.org/10.1097/00006123-200211000-00010

[8] Sun, J.J., Wang, Z.Y., Li, Z.D. and Liu, B. (2009) Microsurgical Treatment and Functional Outcomes of Multi-Segment Intramedullary Spinal Cord Tumors. Journal of Clinical Neuroscience, 16, 666-671. https://doi.org/10.1016/j.jocn.2008.08.016

[9] Berhouma, M., Bahri, K., Houissa, S., Zemmel, I., Khouja, N., Aouidj, L., Jemel, H. and Khaldi, M. (2009) Management of Intramedullary Spinal Cord Tumors: Surgical 
Considerations and Results in 45 Cases. Neurochirurgie, 55, 293-302.

https://doi.org/10.1016/j.jocn.2008.08.016

[10] Sandalcioglu, I.E., Gasser, T., Asgari, S., Lazorisak, A., Engelhorn, T., Egelhof, T., Stolke, D. and Wiedemayer, H. (2005) Functional Outcome after Surgical Treatment of Intramedullary Spinal Cord Tumors: Experience with 78 Patients. Spinal Cord, 43, 34-41. https://doi.org/10.1016/j.jocn.2008.08.016

[11] Chamberlain, M.C. and Tredway, T.L. (2011) Adult Primary Intradural Spinal Cord Tumors: A Review. Current Neurology and Neuroscience Reports, 11, 320-328. https://doi.org/10.1007/s11910-011-0190-2 